\title{
Current and emerging therapies for primary central nervous system lymphoma
}

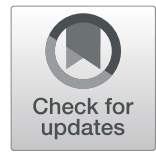

Yan Yuan', Tianling Ding ${ }^{1}$, Shu Wang ${ }^{1}$, Hong Chen ${ }^{2}$, Ying Mao ${ }^{3^{*}}$ and Tong Chen ${ }^{1 *}$ (D)

\begin{abstract}
Primary central nervous system (CNS) lymphoma (PCNSL) is a rare type of extranodal lymphoma exclusively involving the CNS at the onset, with diffuse large B-cell lymphoma (DLBCL) as the most common histological subtype. As PCNSL is a malignancy arising in an immune-privileged site, suboptimal delivery of systemic agents into tumor tissues results in poorer outcomes in PCNSL than in non-CNS DLBCLs. Commonly used regimens for PCNSL include high-dose methotrexate-based chemotherapy with rituximab for induction therapy and intensive chemotherapy followed by autologous hematopoietic stem cell transplantation or whole-brain radiotherapy for consolidation therapy. Targeted agents against the B-cell receptor signaling pathway, microenvironment immunomodulation and blood-brain barrier (BBB) permeabilization appear to be promising in treating refractory/ relapsed patients. Chimeric antigen receptor-T cells (CAR-T cells) have been shown to penetrate the BBB as a potential tool to manipulate this disease entity while controlling CAR-T cell-related encephalopathy syndrome. Future approaches may stratify patients according to age, performance status, molecular biomarkers and cellular bioinformation. This review summarizes the current therapies and emerging agents in clinical development for PCNSL treatment.

Keywords: primary central nervous system lymphoma, diffuse large B-cell lymphoma, targeted therapy
\end{abstract}

\section{Introduction}

Primary central nervous system (CNS) lymphoma (PCNSL) is an aggressive extranodal lymphoma exclusively involving the brain, spinal cord, cranial nerves, leptomeninges and eyes, with diffuse large B-cell lymphoma (DLBCL) as the most common subtype [1]. The incidence of PCNSL appears to be increasing according to the data from Surveillance, Epidemiology and End Results registries. The highest rates were observed among those age $\geq 65$ years. The age-adjusted incidence of PCNSL is $0.16(0.14-0.18)$ per 100,000, showing 3-fold increase of extracranial DLBCL between 1985-1997 [2]. CNS infiltration secondary to systemic DLBCLs or

\footnotetext{
* Correspondence: chentong@fudan.edu.cn; maoying@fudan.edu.cn 'Department of Hematology, Huashan Hospital, Fudan University, 12 Wulumuqi Middle Road, Shanghai 200040, China

${ }^{3}$ Department of Neurosurgery, Huashan Hospital, Fudan University, 12 Wulumugi Middle Road, Shanghai 200040, China

Full list of author information is available at the end of the article
}

lymphomas occurring in immunodeficient patients is excluded from this disease entity [3]. Owing to the limitations of the cranial cavity, patients with PCNSL have intracranial hypertension together with abnormal brain function at presentation and recurrence, showing symptoms of confusion, headache, nausea, vomiting, disorientation, dystaxia, epilepsy, or hemiplegic paralysis with rapid progression [4]. The existence of the blood-brain barrier (BBB) is a major cause of the suboptimal delivery of chemotherapeutic drugs into the CNS, resulting in poorer outcomes in PCNSL than in non-CNS lymphomas [5]. Despite the dramatic therapeutic effects of anti-CD20 antibodies on extracranial mature B cell tumors, the concentration of CD20 antibodies in the cerebrospinal fluid (CSF) is estimated to be $0.14 \%$ of that in the peripheral blood [6], raising the point that the overall therapeutic status of PCNSL is lagging in the prerituximab $(R)$ era. 
A multidisciplinary collaboration is important to control this disease entity. Given the low incidence of PCNS $\mathrm{L}$ and the requirement for intraoperative navigation techniques in stereotactic brain biopsy, far fewer randomized clinical trials have been conducted on PCNSL than on non-CNS lymphomas [7]. The current therapeutic strategy can be divided as induction, consolidation and maintenance phases and primarily relies on a high-dose (HD) methotrexate (MTX, M)-based regimen followed by whole-brain radiotherapy (WBRT) [8,9] or autologous hematopoietic stem cell transplantation (ASCT) [10]. Considering the dose-dependent BBB penetration of cytotoxic agents, balancing the efficiency and side effects of HD chemotherapy remains a major challenge.

Recently, a number of targeted therapies have shown success in treating non-CNS B-cell malignancies [1113]. Some of these agents showed benefits in preventing disease progression and extending patient survival, providing insight for the future of PCNSL treatment [14, 15]. In this review, we focused on discussing current and emerging therapeutic strategies for this disease entity (Figure 1).

\section{Diagnosis and pretreatment evaluation}

The symptoms of PCNSL are similar to other brain tumors, indicating that the pathological criteria are important in differential diagnosis. As lymphoma cells in newly diagnosed (ND) cases are sensitive to corticosteroids, presteroid biopsy is highly recommended in suspected cases [16]. However, disappearance of the tumor mass after steroid treatment highly indicates its lymphocytic origin, guiding the necessity of interval follow-up and later rebiopsy. In some cases with meningeal infiltration, investigations of the CSF, including cytology, flow cytometry analysis, immunohistochemistry,

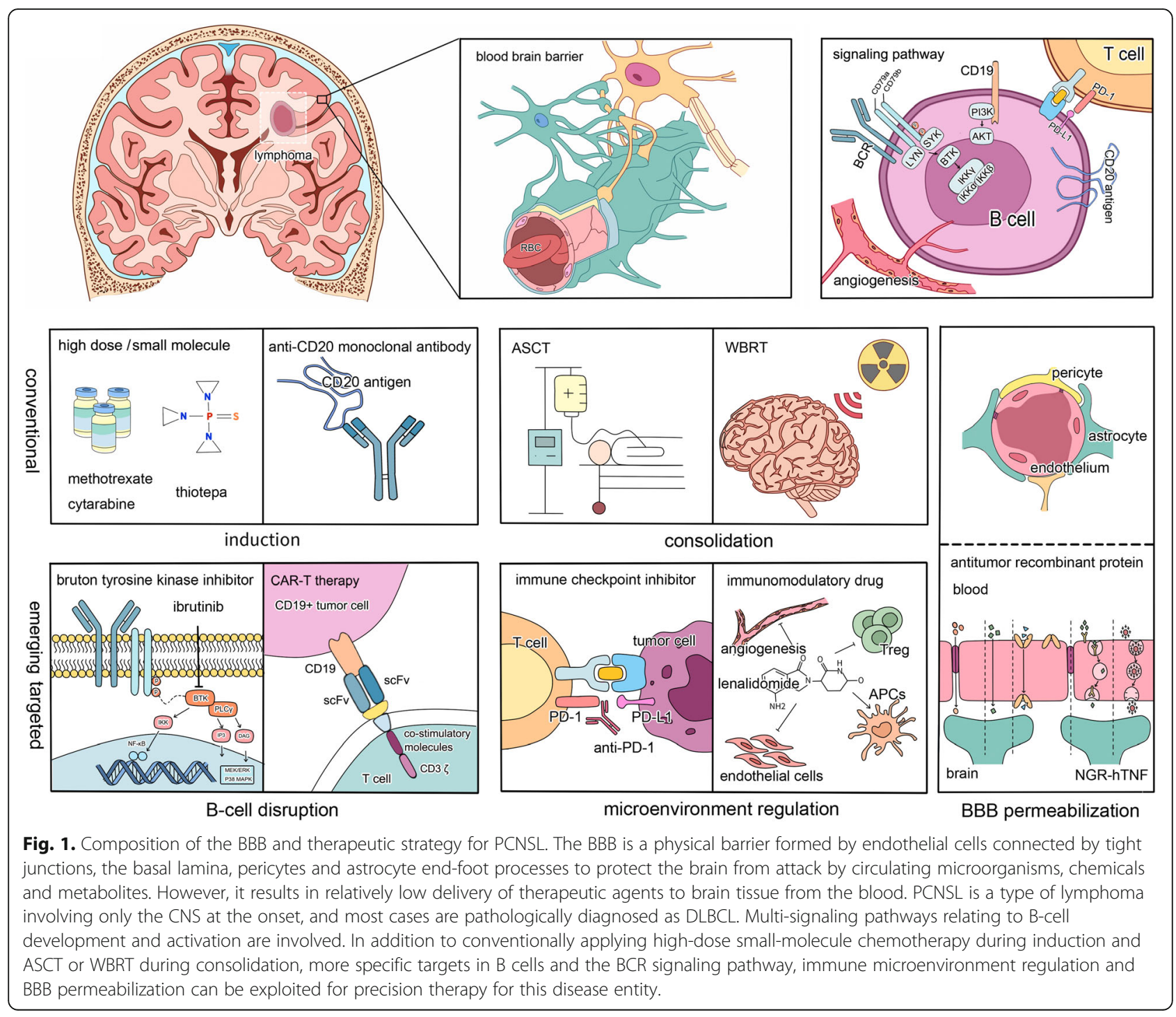


evaluation of immunoglobulin heavy chain $(\operatorname{IgH})$ rearrangement and detection of other possible genes, are helpful in making an accurate diagnosis [17].

According to the World Health Organization (WHO) classification of tumors of hematopoietic and lymphoid tissue published in 2016 [18], the term primary CNS lymphoma is designated as primary CNS DLBCLs, the majority of which are classified as the non-germinal center B-cell-like (non-GCB) type by cell-of-origin classification with a typical immunohistochemical profile of $\mathrm{CD} 19^{+} \mathrm{CD} 20^{+} \mathrm{CD}^{-} \mathrm{CD}^{-} 0^{-} \mathrm{BCL}^{-}$

or

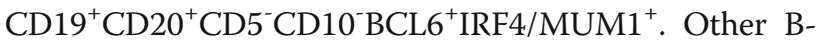
cell lymphomas with a high tendency to occur within the CNS and pathologically mimic primary CNS DLBCLs, including Burkitt lymphomas, Epstein-Barr virus (EBV)-positive DLBCL, and lymphomatoid granulomatosis, require to be differentiated [19]. As more profound subclassification of DLBCL cases is indicated by analysis of mutated genes [20,21], detection of EBVEBER and genetic testing of $M Y C$ translocation, BCL2, $B C L 6$, and $I g H$ rearrangement, as well as testing for mutations in MYD88 and CD79B, will help to provide more information to aid in interpreting pathologic diagnosis.

To exclude other systemic B-cell malignancies related to CNS infiltration and intraocular involvement, other examinations, including positron emission tomography with computed tomography, bone marrow biopsy/aspirate with flow cytometry analysis, lumbar puncture with
CSF detection, fundoscopy and slit lamp microscopy, are necessary for diagnosis and staging [22]. For patients with suspected intraocular lymphoma, optical coherence tomography and vitrectomy are essential for diagnosis, which is aided by immunocytochemistry, flow cytometry, monitoring the interleukin (IL)-10/IL-6 concentration ratio $(>1)$ and clonal detection [23].

\section{Current therapies for PCNSL}

The cutoff for the molecular weight of compounds efficiently penetrating the BBB is $400-600 \mathrm{Da}$ [24]. The majority of the chemotherapeutics currently used to treat PCNSL are small molecules matching this standard and have various BBB penetration efficiencies (Table 1) [14, 15, 25-46].

Conventional therapy for PCNSL is still staged for induction and consolidation phases. In 2020, the National Comprehensive Cancer Network (NCCN) guidelines recommend systemic therapy for ND patients suitable for or capable of tolerating HD chemotherapy, while for unfit patients, 24-36 Gy of WBRT with a boost to gross disease for a total of $45 \mathrm{~Gy}$ is indicated. For ND patients, the first recommendation is HD-MTX at $8 \mathrm{~g} / \mathrm{m}^{2}$ with rituximab and temozolomide (TMZ) or a reduced dose of $3.5 \mathrm{~g} / \mathrm{m}^{2}$ MTX with $\mathrm{R}$, vincristine and procarbazine (RMVP) as well as WBRT [47-49]. When complete remission (CR) or unconfirmed CR (CRu) is achieved, ASCT, low-dose WBRT (23.4 Gy) or continuous monthly MTX

Table 1 Pharmacokinetics of Agents Recommended by NCCN Guideline for PCNSL

\begin{tabular}{|c|c|c|c|c|c|c|c|}
\hline & Preferred regimens & Agent $^{a}$ & $\begin{array}{l}\text { MW } \\
(\mathrm{Da})\end{array}$ & Route & $\begin{array}{l}\text { Protein binding } \\
(\%)\end{array}$ & $\begin{array}{l}\text { CSF (brain)/blood } \\
\text { (\%) }\end{array}$ & Reference \\
\hline \multirow[t]{5}{*}{ Induction } & \multirow{5}{*}{$\begin{array}{l}\text { R+MTX(8) } \\
\text { R+MTX(8)+ TMZ } \\
\text { R+M(3.5)VP(+WBRT in con.) } \\
\text { R+MTX(3.5)+TMZ(+WBRT in } \\
\text { con.) }\end{array}$} & MTX(M) & 454 & iv & $46.5-54$ & $2-20$ & {$[25,26]$} \\
\hline & & rituximab(R) & 143857 & iv & NA & 0.1 & {$[27,28]$} \\
\hline & & temozolomide (TMZ) & 194 & oral & 15 & $20-30$ & [29-31] \\
\hline & & procarbazine(P) & 221 & oral & NA & NA & [32] \\
\hline & & vincristine( $(V)$ & 824 & iv & 75 & undetected & [33] \\
\hline \multirow[t]{6}{*}{ Consolidation } & \multirow{6}{*}{$\begin{array}{l}\text { ASCT with condition regimen } \\
\text { BCNU+T } \\
\text { TBC } \\
\text { HD-AraC( } \pm \text { VP16) }\end{array}$} & thiotepa(T) & 189 & iv & NA & $95-100$ & [34] \\
\hline & & carmustine (BCNU) & 214 & iv & 80 & $20-30$ & [35] \\
\hline & & Busulfan(B) & 246 & iv & 32 & 95 & [36] \\
\hline & & cyclophosphamide(C) & 261 & iv & 20 & 50 & [37] \\
\hline & & etoposide (VP16) & 589 & iv & 97 & $0.5-5$ & [38] \\
\hline & & cytarabine (AraC) & 243 & iv & 13 & $6-22$ & {$[39,40]$} \\
\hline \multirow{6}{*}{$\begin{array}{l}\text { Refractory/ } \\
\text { Relapse }\end{array}$} & \multirow{6}{*}{$\begin{array}{l}\text { Retreat with HD-MTX } \\
\pm R \\
+R+i b r u t i n i b \\
\text { Ibrutinib } \\
\text { TMZ } \\
\text { Lenalidomide or others }\end{array}$} & ibrutinib & 440 & oral & irreversible & $1-20\left(28.7^{\complement}\right)$ & {$[14,41]$} \\
\hline & & lenalidomide & 259 & oral & 30 & $11^{\mathrm{p}}-20$ & {$[42,43]$} \\
\hline & & topotecan & 421 & iv/oral & 35 & $13-68$ & [44] \\
\hline & & cisplatin & 300 & iv & 90 & 50 & [45] \\
\hline & & pemetrexed & 427 & iv & 81 & $<5$ & [46] \\
\hline & & pomalidomide & 273 & oral & $12-44$ & $17-19$ & [15] \\
\hline
\end{tabular}

Abbreviations: $a$ associated conditions collected from the public data sources of drugbank (https://www.drugbank.ca/drugs); $c$ corrected for protein binding; con consolidation; CSF cerebrospinal fluid; iv intravenous; MTX methotrexate $\left(\mathrm{g} / \mathrm{m}^{2}\right)$; $M V$ molecular weight; NA not available; NCCN national comprehensive cancer network; $p$ nonhuman primates 
administration can be performed as a consolidation therapy, while for patients unable to achieve $\mathrm{CR}$ or $\mathrm{CRu}$, WBRT at a dose of 30-36 Gy with a boost to $45 \mathrm{~Gy}$ should be performed $[9,49,50]$.

\section{Combined chemoimmunotherapy in the induction phase}

The standard regimen of induction chemotherapy has been modified since the 1970s, with HD-MTX serving as the main backbone (Fig. 2). Additionally, combined agents, including rituximab, cytarabine (AraC, A), temozolomide, procarbazine, vincristine and WBRT, have been evaluated in some randomized clinical trials (Table 2) [51-57], while the regimen of MVP and the addition of rituximab were both described in the early 2000s.

Although the role of rituximab in treating PCNSL has been debated for decades, in consideration of its lower delivery in brain tissue, it is incorporated in the most present treatment protocol due to favorable safely spectrum. Apart from some cases of intrathecal injection, rituximab was recently documented to be administered as intravenous infusion at a dose of $375-500 \mathrm{mg} /$ $\mathrm{m}^{2}$ weekly or every $2-3$ weeks $[61,62]$. Two randomized controlled trials (RCTs) designed to compare the outcome of rituximab therapy in PCNSL reported contradicting findings in 2016 and 2019 (Table 2) [54, 56]. One indicated that the addition of rituximab achieved a significantly improved response rate [54], while the other found no clear benefit, although patients $<60$ years old showed an improved response [56]. The difference in the evaluated endpoint and whether or not WBRT was subsequently applied during consolidation may be the major causes of the opposite conclusions.

The incidence of PCNSL is increased in elderly patients; thus, age is an important factor affecting comorbidities, organ dysfunction and iatrogenic neurotoxicity, all of which are fundamental elements impacting patients' overall survival (OS) and quality of life (QoL). The outcomes of elderly patients $>70$ years old, who have a median survival time of 6-7 months, are still challenged, and the fraction of untreated patients $>80$ years old is dramatically increased $[63,64]$. Finding a balance between minimizing toxicity and prolonging survival is complex work indeed.

\section{ASCT vs WBRT in the consolidation phase}

Neurocognitive toxicity is an inevitable side effect of WBRT, and longitudinal neuropsychological assessments need to be performed pre- and post-treatment. Patients undergoing WBRT may exhibit no significant difference in progression-free survival (PFS) or OS at the expense of a decreased global health status, unfavorable physical function and worsened future uncertainty (Table 2) [57, $59,65]$. These issues have raised great interest in evaluating the role of intensive chemotherapy in PCNSL with hematopoietic reconstitution by ASCT [66].

The conditioning regimens used for ASCT have been modified to include drugs with higher delivery into the CNS, and HD thiotepa (T), busulfan (B), cyclophosphamide (C, CTX), AraC, carmustine (BCNU), melphalan

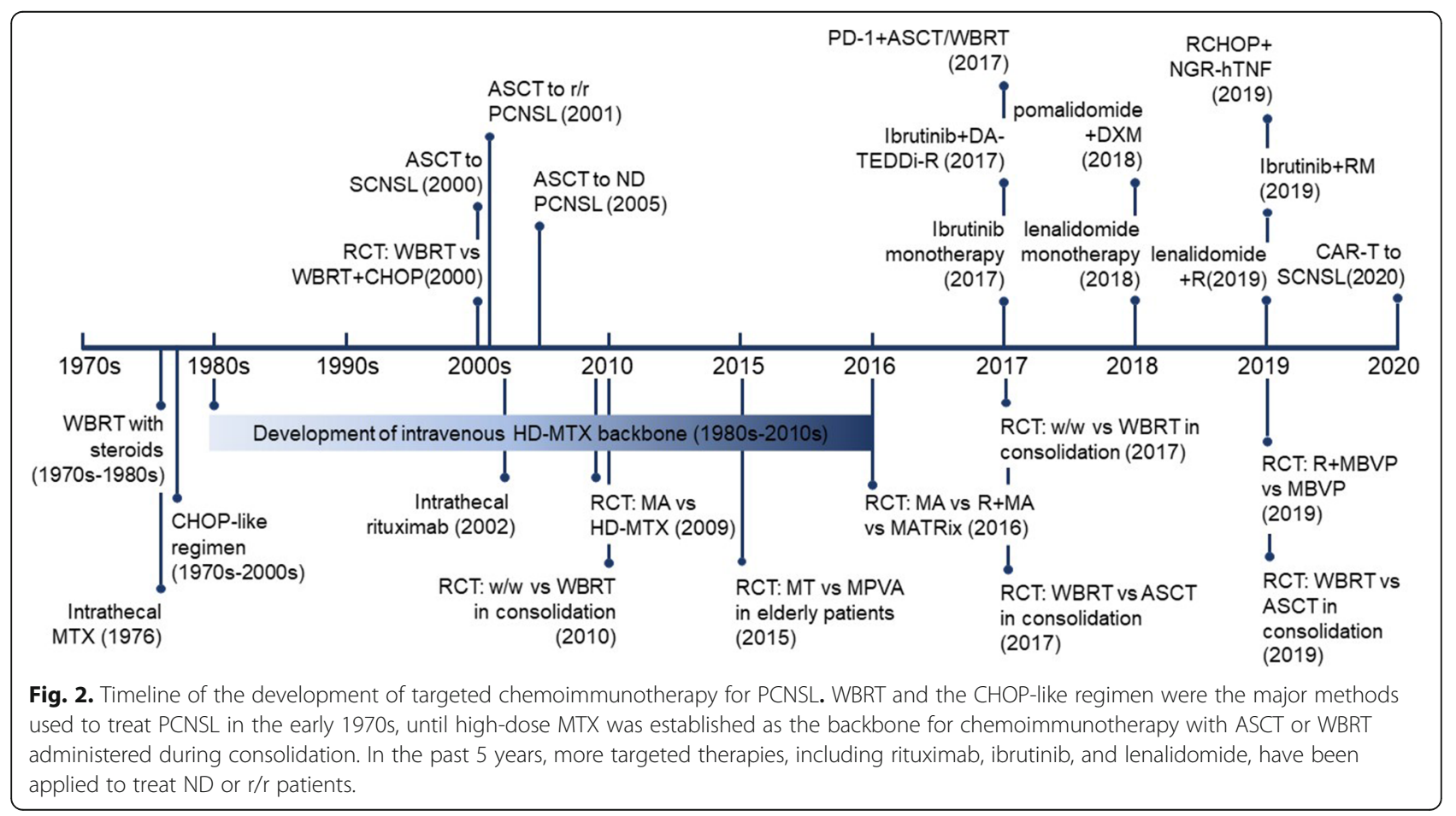




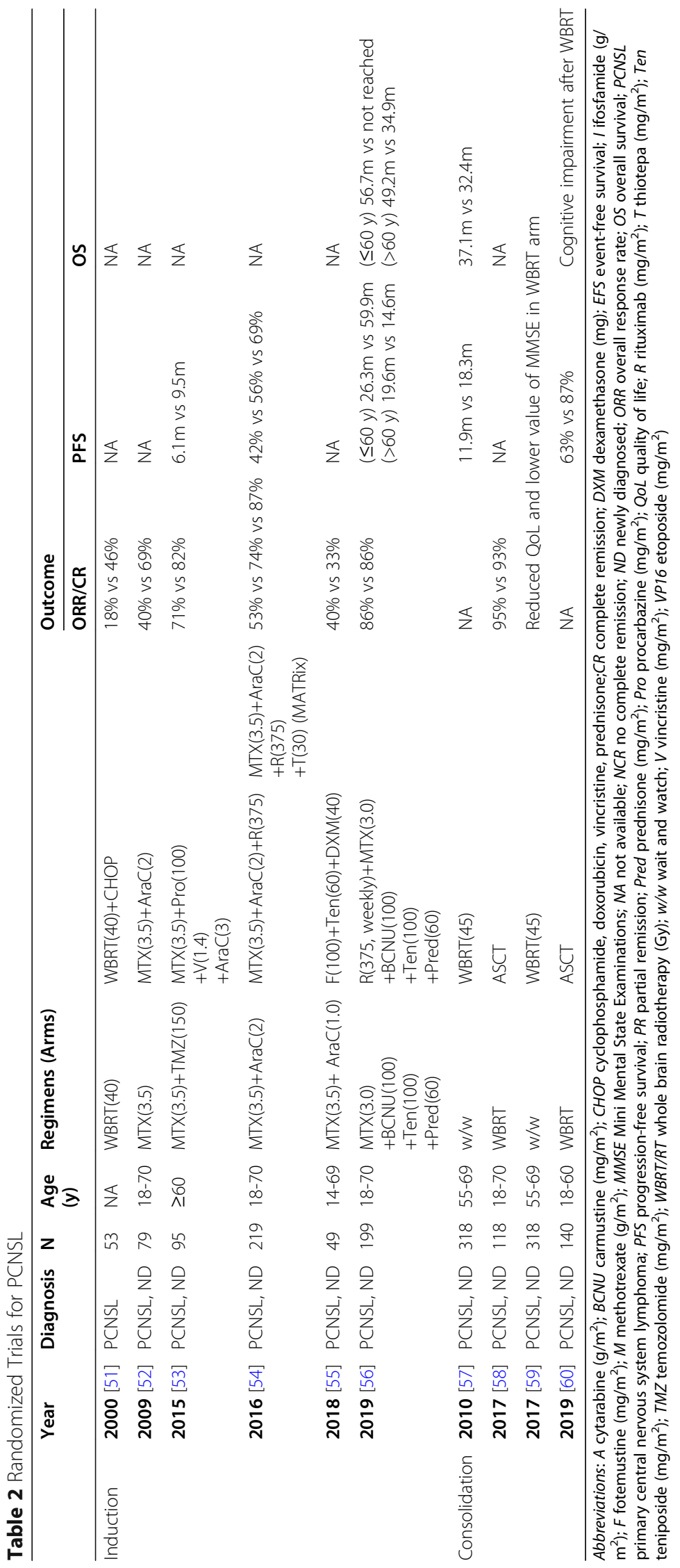


and etoposide (VP16, E) are relatively frequently applied (Table 1) $[67,68]$. Among these agents, thiotepa exhibits a higher capability to distribute into the CNS following systemic injection and shows an equilibrated concentration between CSF and plasma at 15 minutes postinjection [69]. Compared to other conditioning agents, the regimens including thiotepa show better outcomes and are recommended as the optimal preparation for ASCT (Table 1) [7].

More recently, RCTs evaluating the efficacy and toxicity of first-line consolidation therapies have reported that both intensive therapy with either ASCT or WBRT is effective in PCNSL patients younger than 60 years old, but the patients receiving WBRT exhibit more impacted cognitive disorders (Table 2) [58,60]. The risks and implications of cognitive impairment after WBRT should be considered when making therapeutic decisions. For the patients younger than 65 years with good performance status, ASCT might be a better choice considering the QoL in an expected long term of survival. However, for the unfit patients $\geq 65$ years or showing symptoms contraindicated to HD chemotherapy, a reduced WBRT will be preferred in consolidation phase.

\section{Novel targeted therapies and emerging agents}

Apart from CD20-targeted rituximab, new findings related to the molecular pathways and pathogenesis of Bcell malignancies have launched the exploration of targeted therapies for PCNSL treatment, most of which are focused on the B cell-related signaling pathway, the immunomodulatory microenvironment, immune checkpoints and BBB permeabilization. These novel targeted agents are creating a new era of precision therapy in the field of PCNSL treatment (Fig. 1, Table 3). The related adverse events (AEs) were listed in Table 4.

\section{Bruton tyrosine kinase inhibitor (BTKi)}

The pathogenesis of the non-GCB type of PCNSL involves a $\mathrm{B}$ cell-activating process after $\mathrm{B}$ cells migrate from the dark zone to the light zone, which leads to activation of B-cell antigen receptor (BCR) and induces NF$\kappa \mathrm{B}$-mediated cell proliferation [82]. BTK is a factor in the downstream signaling pathway, serving as an inhibitor of Fas-induced apoptosis in B lymphocytes [83] and playing a role in $\mathrm{B}$ cell development independent from the myeloid signaling pathway [84]. A single amino acid substitution or multiple mutations in BTK mediate the phenotype of X-linked immunodeficiency in humans and mice, displaying defects in cyclins and cycle entry blockade in B cells [85].

Ibrutinib, the first-in-class BTKi, exerts a specific function to disrupt $\mathrm{BCR}$ signaling. As a unique smallmolecule inhibitor selectively binding to BTK in the context of a complex proteome to inhibit B cell activation
[86], ibrutinib has succeeded in treating some mature Bcell neoplasms, including chronic lymphocytic leukemia (CLL) [11], mantle cell lymphoma [12], and Waldenström macroglobulinemia [87], as well as some nonGCB-type DLBCLs [88]. Ibrutinib has been reported to significantly block the anti-IgM-induced cellular survival and DNA replication of CLL cells [89]. The second generation of BTKis including zanubrutinib (BGB-3111), acalabrutinib (ACP-196) and orelabrutinib (ICP-022) show more selectivity for the BTK pathway and less offtarget effects on EGFR, TEC, IL-2 tyrosine kinase, and other kinases [90], increasing the efficacy and safety in B-cell malignancy treatment $[91,92]$.

To date the potential relevant of ibrutinib to PCNSL, the pharmacokinetics of ibrutinib and its primary metabolite, PCI-45227 was investigated either in plasma or in CSF. Interestingly, free ibrutinib achieved significant CNS penetration at doses from $560 \mathrm{mg}$ to $840 \mathrm{mg}$, with a $28.7 \%$ CSF/plasma ratio after correction for protein binding (Table 1) [14]. Another preclinical study also provided evidence of the BBB-permeabilizing efficiency of ibrutinib, showing that ibrutinib rapidly crossed the BBB in 0.29 h (0.2-0.32 h) [41].

The first successful therapeutic application of a BTKi in PCNSL was published in 2017. Eighteen patients with relapsed/refractory $(r / r)$ PCNSL were treated with 560$840 \mathrm{mg}$ of ibrutinib combined with a chemotherapy regimen, most of which were a DA-TEDDi-R regimen including temozolomide, etoposide, liposomal doxorubicin, dexamethasone, ibrutinib, rituximab, pegfigrastim and intrathecal injection of AraC. Twelve of 14 evaluated patients achieved $\mathrm{CR}$ or $\mathrm{CRu}$, and $57 \%(8 / 14)$ of the patients continued to be progression-free at a median time of 15.5 months of follow-up. The median PFS time was 15.3 months, while median OS endpoint was not reached [14]. Two other designed ibrutinib doseescalation studies at a daily dose from $560 \mathrm{mg}$ to $840 \mathrm{mg}$ showed 12/15 (80\%) and 10/13 (77\%) of patients achieved a response, including eight and five CRs, respectively [70, 72]. Another phase I/II study enrolled 44 $\mathrm{r} / \mathrm{r}$ PCNSL patients with orally dose escalating tirabrutinib, a second generation BTKi in Japan. Independent review committee assessed overall response rate (ORR) of $64 \%(5 \mathrm{CR} / \mathrm{CRu})$ at $320 \mathrm{mg}, 100 \%(4 \mathrm{CR} / \mathrm{CRu})$ at 480 $\mathrm{mg}$, and $53 \%(6 \mathrm{CR} / \mathrm{CRu})$ at $480 \mathrm{mg}$ under fasted condition [74]. However, ibrutinib monotherapy produced shorter PFS than combined therapy [14, 71, 72, 93].

The optimal combination of chemotherapy with BTKis has not yet been developed. In a study on DA-TEDDi-R, the antifolate agents, including methotrexate, did not exhibit synergistic action with ibrutinib in a cytotoxicity assay performed with TMD8 and OCI-Ly10 lymphoma cells, while the DNA-damaging agents did. Instead, an antagonist representative DBSumNeg metric value 
Table 3 Novel Targeted Therapies for CNS Lymphoma

\begin{tabular}{|c|c|c|c|c|c|c|c|}
\hline Author & Year & Diagnosis & $\mathbf{N}$ & Study & $\begin{array}{l}\text { Age } \\
\text { (year) }\end{array}$ & Regimen & Outcome \\
\hline \multicolumn{8}{|l|}{ BTKi } \\
\hline $\begin{array}{l}\text { Grommes C. et al } \\
{[70]}\end{array}$ & 2017 & $\begin{array}{l}\text { PCNSL/SCNSL, } \\
r / r\end{array}$ & 20 & phase I & $21-85$ & ibrutinib monotherapy & ORR: 10/13, CR 5, PR 5 \\
\hline $\begin{array}{l}\text { Lionakis MS. et al } \\
{[14]}\end{array}$ & 2017 & $\begin{array}{l}\text { PCNSL, ND } \\
\text { and } r / r\end{array}$ & 18 & phase Ib & $49-87$ & ibrutinib + DA-TEDDi-R & CR+CRu 16/18 \\
\hline $\begin{array}{l}\text { Soussain C. et al } \\
\text { [71] }\end{array}$ & 2019 & $\begin{array}{l}\text { PCNSL/PVRL, } \\
r / r\end{array}$ & 52 & phase II & $47-82$ & ibrutinib monotherapy & ORR: $59 \%$, mean PFS $4.8 \mathrm{~m}$, mean OS $19.2 \mathrm{~m}$ \\
\hline $\begin{array}{l}\text { Grommes C. et al } \\
\text { [72] }\end{array}$ & 2019 & $\begin{array}{l}\text { PCNSL/SCNSL, } \\
r / r\end{array}$ & 15 & phase Ib & $23-74$ & ibrutinib + MTX+R & ORR: 12/15 \\
\hline Chen F. et al [73] & 2020 & PCNSL, ND & 11 & retrospective & $41-68$ & Ibrutinib+MTX & ORR $81.8 \%$ \\
\hline Narita Y. et al [74] & 2021 & PCNSL, r/r & 44 & phase $\mid / \|$ & $29-86$ & tirabrutinib monotherapy & $\begin{array}{l}>60 \% \text { at } 320 \mathrm{mg}, 100 \% \text { at } 480 \mathrm{mg} \text {, and } 53 \% \text { at } \\
480 \mathrm{mg} \text { (fasted) }\end{array}$ \\
\hline \multicolumn{8}{|l|}{ IMids } \\
\hline $\begin{array}{l}\text { Rubenstein JL. } \\
\text { et al [42] }\end{array}$ & 2018 & $\begin{array}{l}\text { PCNSL/SCNSL, } \\
r / r\end{array}$ & 14 & phase I & $47-79$ & $\begin{array}{l}\text { lenalidomide or } \\
\text { lenalidomide }+R\end{array}$ & ORR: 64\% \\
\hline $\begin{array}{l}\text { Tun HW. et al } \\
{[15]}\end{array}$ & 2018 & $\begin{array}{l}\text { PCNSL/PVRL, } \\
r / r\end{array}$ & 25 & phase I & adults & pomalidomide+DXM & ORR: $48 \%$ \\
\hline Vu K. et al [75] & 2019 & PCNSL/SCNSL & 13 & retrospective & $70-86$ & $\begin{array}{l}\text { lenalidomide in } \\
\text { maintenance }\end{array}$ & mean PFS: not reached \\
\hline $\begin{array}{l}\text { Ghesquieres } \\
\text { H.et al [76] }\end{array}$ & 2019 & $\begin{array}{l}\text { PCNSL/PVRL, } \\
r / r\end{array}$ & 50 & phase II & $46-86$ & lenalidomide+R & ORR: $35.6 \%$ \\
\hline \multicolumn{8}{|l|}{ PD-1 antibody } \\
\hline Nayak L. et al [77] & 2017 & $\begin{array}{l}\text { PCNSL/SCNSL, } \\
r / r\end{array}$ & 5 & case report & $54-85$ & nivolumab+RWBRT & CR 4, PR 1 \\
\hline \multicolumn{8}{|l|}{ BBB permeabilization } \\
\hline $\begin{array}{l}\text { Ferreri AJM. et al } \\
{[78]}\end{array}$ & 2020 & PCNSL, r/r & 28 & phase II & $26-78$ & NGR-hTNF/R-CHOP & ORR: 75\%; CR 11, PR 10 \\
\hline \multicolumn{8}{|l|}{ CAR-T } \\
\hline Tu S. et al [79] & 2019 & PCNSL, r/r & 1 & case report & 67 & CD19-CD70 dual CART & $C R$ \\
\hline $\begin{array}{l}\text { Abbasi A. et al } \\
{[80]}\end{array}$ & 2020 & SCNSL, r/r & 2 & retrospective & NA & axicabtagene ciloleucel & CR 2 \\
\hline $\begin{array}{l}\text { Abramson JS. } \\
\text { et al [81] }\end{array}$ & 2020 & SCNSL, r/r & 7 & prospective & NA & lisocabtagene maraleucel & CR 3 (of 6 evaluated) \\
\hline
\end{tabular}

Abbreviations: CART chimeric antigen receptor T cells; CNS central nervous system; CR complete remission; CRu complete remission unconfirmed; DA-TEDDi-R etoposide, temozolomide, liposomal doxorubicin, dexamethasone, intrathecal cytarabinem; DXM dexamethasone; MTX methotrexate; NA not available; ND newly diagnosed; NGR-hTNF tumor necrosis factor-a coupled with CNGRCG peptide; ORR overall response rate, OS overall survival, PCNSL primary central nervous system lymphoma; PFS progression-free survival; $P R$ partial remission, $P V R L$ primary vitreoretinal lymphoma; $R$ rituximab; $r / r$ refractory/relapse; SCNSL secondary central nervous system lymphoma; WBRT whole brain radiotherapy

indicated the antagonistic relationship between ibrutinib and multiple antifolates [14]. However, another ibrutinib-based regimen combined with HD-MTX did show an increased $80 \%(12 / 15)$ response in $\mathrm{r} / \mathrm{r}$ patients [72]. Recently, a real-world experience of combining ibrutinib with HD-MTX in treating ND PCNSL patients reported $81.8 \%$ of ORR with mind tolerable anemia, hypoalbuminemia and hypokalemia, indicating a potential role of BTKi in the frontline treatment [73]. A couple of BTKi-based trials evaluating ibrutinib, acalabritinb or orelabrutinib in combination with the agents HD-MTX, R-MVP, MRE, lenalidomide or an anti-programmed death (PD)-1 antibody are currently ongoing (Table 5).
The standard regimen and the functions of various BTKis remain to be determined.

Tyrosine kinase signaling is also required for the innate immune system and T cell function. BTK-deficient macrophages lack IL-10 production, which is stimulated by Toll-like receptor activation, and nuclear localization of NF- $\mathrm{kB}$ and AP-1 [94]. Aspergillus fumigatus-stimulating phagocytosis was indicated to be mediated by BTK signaling and was inhibited by BTK-siRNA or ibrutinib [95]. BTKis also inhibit IL-2-inducible T-cell kinase (ITK) signaling in the $\mathrm{CD}_{4}^{+} \mathrm{T}$ helper 2 (Th2) cell population, which causes failures in protection against pathogens [96]. As every coin has two sides, the impact of 
Table 4 Major AEs of Targeted Therapies for CNS Lymphoma

\begin{tabular}{|c|c|c|c|}
\hline \multirow[t]{2}{*}{ Targeted therapy } & \multicolumn{3}{|l|}{ Adverse events } \\
\hline & Events & Any grade & Grade $\geq 3$ \\
\hline \multirow[t]{10}{*}{ ibrutinib [14, 70-72] } & neutropenia & $25 \%(5 / 20) \sim 40 \%(6 / 15)$ & $3.8 \%(2 / 52) \sim 83 \%(15 / 18)$ \\
\hline & anemia & 70\%(14/20) 100\%(15/15) & 5\%(1/20) 20\%(3/15) \\
\hline & thrombocytopenia & $70 \%(14 / 20)$ & 10\%(2/20) 72\%(13/18) \\
\hline & febrile neutropenia & $5 \%(1 / 25)$ & $1.9 \%(1 / 52) \sim 61 \%(11 / 18)$ \\
\hline & increased creatinine & 27\%(4/15) 30\%(6/20) & $27 \%(4 / 15)$ \\
\hline & increased ALT & $3.8 \%(2 / 52) \sim 80 \%(12 / 15)$ & 7\%(1/15) 10\%(2/20) \\
\hline & diarrhea & $3.8 \%(2 / 52) \sim 25 \%(5 / 20)$ & 7\%(1/15) 11\%(2/18) \\
\hline & prolonged APTT & $20 \%(3 / 15) \sim 30 \%(6 / 20)$ & $10 \%(2 / 20)$ \\
\hline & infection & $9.6 \%(5 / 52) \sim 27 \%(4 / 15)$ & $5.8 \%(3 / 52) \sim 78 \%(14 / 18)$ \\
\hline & atrial fibrillation & $3.8 \%(2 / 52)$ & $1.9 \%(1 / 52)$ \\
\hline \multirow[t]{4}{*}{ lenalidomide $[42,76]$} & neutropenia & & $21.4 \%(3 / 14) \sim 40 \%(20 / 50)$ \\
\hline & thrombocytopenia & & $10 \%(5 / 50)$ \\
\hline & anemia & & $4 \%(2 / 50)$ \\
\hline & infection & & $8 \%(4 / 50) \sim 21.4 \%(3 / 14)$ \\
\hline \multirow[t]{7}{*}{ Pomalidomide [15] } & neutropenia & $100 \%(25 / 25)$ & $20 \%(5 / 25)$ \\
\hline & thrombocytopenia & $44 \%(11 / 25)$ & $8 \%(2 / 25)$ \\
\hline & anemia & $80 \%(20 / 25)$ & $8 \%(2 / 25)$ \\
\hline & thromboembolism & $8 \%(2 / 25)$ & \\
\hline & infection & $44 \%(11 / 25)$ & $16 \%(4 / 25)$ \\
\hline & fatigue & $40 \%(10 / 25)$ & $8 \%(2 / 25)$ \\
\hline & dyspnea, hypoxia and/or respiratory failure & $16 \%(4 / 25)$ & $16 \%(4 / 25)$ \\
\hline \multirow[t]{3}{*}{ nivolumab [77] } & pruritus & $20 \%(1 / 5)$ & \\
\hline & fatigue & $20 \%(1 / 5)$ & \\
\hline & renal insufficiency & $20 \%(1 / 5)$ & $20 \%(1 / 5)$ \\
\hline \multirow[t]{8}{*}{ NGR-hTNF [78] } & neutropenia & $89 \%(25 / 28)$ & $85 \%(24 / 28)$ \\
\hline & thrombocytopenia & $85 \%(24 / 28)$ & $61 \%(17 / 28)$ \\
\hline & anemia & $85 \%(24 / 28)$ & $21 \%(6 / 28)$ \\
\hline & febrile neutropenia & $14 \%(4 / 28)$ & $14 \%(4 / 28)$ \\
\hline & infection & $14 \%(4 / 28)$ & $14 \%(4 / 28)$ \\
\hline & deep vein thrombosis & $7 \%(2 / 28)$ & $7 \%(2 / 28)$ \\
\hline & infusion reaction & $32 \%(9 / 28)$ & \\
\hline & hepatotoxicity & $50 \%(14 / 28)$ & $18 \%(5 / 28)$ \\
\hline
\end{tabular}

Abbreviations: ALT alanine aminotransferase, APTT activated partial thromboplastin time

BTKis on cell cycling results in hampered anti-infectious functions of B cells. This AE occurred in $56 \%$ of patients treated with ibrutinib monotherapy and $52 \%$ of patients treated with combined therapy [97], with pulmonary/ CNS aspergillosis being more frequent in the heavily treated group[14, 72, 98].

The relationship between ibrutinib resistance and genetic mutations in CNS lymphoma is still unclarified. Two studies reported genomic findings related to the response to ibrutinib. In an open-label, nonrandomized, dose-escalation ibrutinib monotherapy trial with whole- exon sequencing detection, twenty-six genes were found to be recurrently mutated in PCNSL, and 23 additional genes were attributed to aberrant somatic hypermutation (aSHM). Among the genes, with a high frequency of MYD88 and CD79B mutation, PIM1, BTG2, PRDM1, TOX, and IRF4 were scored as both recurrent mutations and targets of aSHM. In 4/20 patients documented as incompletely response, one patient had a mutation in the coiled-coil domain of CARD11 (R179Q), while the other three had a mutation in CARD11 (R337Q) or inactivating lesions in TNFAIP3 (deletion or frameshift mutation) 
Table 5 Registered BTKi Trials of CNS Lymphoma on ClinicaTrial.gov

\begin{tabular}{|c|c|c|c|c|c|}
\hline Trial & $\mathbf{N}$ & Recruited condition & Study & Intervention regimen & Location \\
\hline NCT03581942 & 45 & $\mathrm{PCNSL}, \mathrm{r} / \mathrm{r}$ & $\mid \mathrm{lb} / \mathrm{II}$ & dose escalation ibrutinib+copanlisib & USA \\
\hline NCT03770416 & 40 & PCNSL/SCNSL, $r / r$ & $\|$ & ibrutinib+nivolumab & USA \\
\hline NCT02315326 & 63 & PCNSL/SCNSL, $r / r$ & $|/| \mid$ & dose escalation ibrutinib+HD-MTX+rituximab & USA \\
\hline NCT02623010 & 30 & PCNSL after CR/PR & $\|$ & ibrutinib in maintenance & Israel \\
\hline NCT03703167 & 40 & PCNSL/SCNSL, $r / r$ & $\mathrm{lb}$ & dose escalation ibrutinib+lenalidomide+rituximab & USA \\
\hline NCT04421560 & 37 & PCNSL, relapse & $\mathrm{Ib} / \|$ & dose escalation ibrutinib+ pembrolizumab +rituximab & USA \\
\hline NCT04129710 & 120 & PCNSL, $r / r$ & $\|, \mathrm{RCT}$ & ibrutinib+MRE vs lenalidomide+MRE & China \\
\hline NCT04066920 & 30 & PCNSL, r/r, transplant ineligible & $\|$ & IBER in induction +ibrutinib in maintenance & Korea \\
\hline NCT02203526 & 52 & PCNSL & I & TEDDi-R+isavuconazole & USA \\
\hline NCT03964090 & 32 & SCNSL & $\|$ & TEDDi-R+isavuconazole & USA \\
\hline NCT04446962 & 128 & PCNSL, ND & $\mathrm{Ib} / \mathrm{Il}$, randomized & dose escalation R-MVP+ibrutinib vs R-MVP+lenalidomide & France \\
\hline NCT04462328 & 21 & PCNSL/SCNSL & I & dose escalation acalabritinb+durvalumab & USA \\
\hline NCT04438044 & 39 & PCNSL/SCNSL, r/r & $\|$ & orelabrutinib & China \\
\hline
\end{tabular}

Abbreviations: BTKi bruton tyrosine kinase inhibitor; CNS central nervous system; $C R$ complete remission; DA-TEDDi-R etoposide, temozolomide, liposomal doxorubicin, dexamethasone, intrathecal cytarabine; HD-MTX high dose methotrexate; IBER ibrutinib, rituximab, ifosfamide and etoposide; MRE methotrexate, rituximab, and etoposide; ND newly diagnosed; $P C N S L$ primary central nervous system lymphoma; $P R$ partial remission; $R C T$ randomized control trial; $R-M V P$ rituximab, methotrexate, procarbazine and vincristine; $r / r$ refractory/relapse; SCNSL secondary central nervous system lymphoma; TEDDi- $R$ temozolomide, etoposide, doxil, dexamethasone, ibrutinib and rituximab

[70]. In another phase Ib trial of rituximab $+3.5 \mathrm{~g} / \mathrm{m}^{2}$ MTX + ibrutinib, the patients were screened with MYD88, CD79B, CARD11, TNFAIP3 and PLCG2. Two patients had progressive disease (PD), and one had stable disease (SD) in this study, all of which had a histological GCB type. One PD patient showed a wild-type genotype, and the other had a CARD11 mutation (T128M/K252E). The SD patient had a PLCG2 mutation (R268W). Interestingly, the patients with mutations in CARD11 exhibited diverse ibrutinib responses (CR, partial response [PR], or PD) [72]. Thus, the specific BTKi resistance gene and whether combined therapy is able to overcome mutation-driven resistance need further investigation.

\section{Immunomodulatory drugs (iMiDs)}

IMiDs are able to increase natural killer (NK) cell cytotoxicity, augment $\mathrm{T}$ cell proliferation, increase production of IL-2 and interferon (INF)- $\gamma$, and modulate IL-12 expression. The synergistical enhancement of NK cellor monocyte-mediated antibody-dependent cellular cytotoxicity has been seen in combining iMiDs and rituximab-treated non-Hodgkin's lymphoma, supporting the use of iMiD-containing treatments in $\mathrm{r} / \mathrm{r}$ B-cell lymphomas [99].

Lenalidomide, a second-generation $\mathrm{iMiD}$, was demonstrated to increase INF- $\beta$ production, downregulate IRF4-SPIB expression and reduce CARD11-transactivating prosurvival $N F-K B$ signaling to synergize with $\mathrm{BTKi}$ to kill activated B-cell type DLBCL cells [100]. The BBB penetration efficiencies of lenalidomide and pomalidomide (Pom) were quantified in two studies. Based on 23 matched plasma-CSF samples, the CSF/plasma ratio of lenalidomide ranged from 0\%-49\%, with dose-dependent CSF penetration efficiencies of $10 \%, 20.4 \%$, and $25.5 \%$ at daily doses of $10 \mathrm{mg}, 15 \mathrm{mg}$, and $20 \mathrm{mg}$, respectively [42]. Pom, a third generation iMiD, exhibits a similar capability for BBB penetration. Approximately 4-4.6 hours after oral administration, the concentration of unbound Pom in the blood and CSF reached 1,100 \pm 82 $\mathrm{ng} / \mathrm{mL}$ and $430 \pm 63 \mathrm{ng} / \mathrm{mL}$ in a rat model, with an unbound $\mathrm{AUC}_{\text {brain }}$ to $\mathrm{AUC}_{\text {blood }}$ ratio of $39 \pm 3 \%$ [101]. In a $\mathrm{r} / \mathrm{r}$ patient treated with a daily dose of $3 \mathrm{mg}$ of Pom, the CSF/blood ratios on day 1 and day 14 were $17 \%$ and $19 \%$, respectively [15].

Lenalidomide monotherapy or lenalidomide+rituximab (R2) combined therapy was applied to treat $\mathrm{r} / \mathrm{r}$ central nervous system lymphomas (CNSLs) during induction or maintenance $[42,75,76]$. Considering BBB penetration efficiency and dose-related AEs, lenalidomide in the $\mathrm{R} 2$ regimen was given at a dose of $15-25 \mathrm{mg} /$ day for 21 days for a 28 -day cycle [42, 76], while a reduced dose of 5-10 mg was reported for maintenance therapy[42, 75]. Interestingly, the response rate of CNSL to iMiDs was associated with the tumor location, while the underlying mechanism has not been identified. According to intention-to-treat data, the ORR of lenalidomide monotherapy was approximately $64 \%$, with a higher response in parenchymal lesions than in leptomeningeal disease (60\% vs 33\%) [42]. Another prospective phase II study conducting R2 induction reported 12 CRs and 10 PRs in 35 cases of PCNSL, with an ORR of $64.7 \%$. However, for patients with vitreoretinal lymphoma, the ocular CR rate was only 35\% [76]. The ORR for Pom treatment was found to be $48 \%$ in $r / r$ PCNSL and primary vitreoretinal 
lymphoma (PVRL) patients [15]. Exciting evidence shows that lenalidomide during maintenance is beneficial for $\mathrm{r} / \mathrm{r}$ patients. The PFS of a cohort of recurrent patients in CR2-CR5 with lenalidomide maintenance was 6 times longer than that in a retrospective cohort of CR1 patients treated with conventional therapy [42].

The grade 3/4 iMiD-related AEs in CNSL are mainly cytopenia, followed by nonhematologic lung infection, sepsis, fatigue, syncope, dyspnea, hypoxia, respiratory failure and rash [42, 76]. No patient had febrile neutropenia $>7$ days in the POM-DXM study [15]. However, the information on iMiDs in PCNSL is still inadequate. Although deletion of Cereblon (CRBN), a target of iMiDs linked with interferon regulatory factor 4 (IRF4), has been associated with iMiD resistance in myeloma, the mechanism of $\mathrm{iMiD}$ resistance in PCNSL has not yet been clarified [102].

\section{Checkpoint inhibitors}

More recently, the expression of checkpoint receptors and their ligands has attracted increasing interest in tumor immune privilege. Some hematologic malignancies, especially Hodgkin's lymphoma, has been demonstrated to overexpress programmed cell death protein (PD)-1 ligand, and anti-PD-1 antibodies block the ability of tumor cells to escape from immune surveillance [103].

PD-1 (CD279), encoded by the gene PDCD1 on chromosome 2q37.3, was first discovered in 1992 [104], and its ligands PD-L1 (CD274) and PD-L2 (CD273) were found to be harbored on 9p24.1 [105-107]. Recurrent genetic features, including gene mutations, copy number alterations (CNAs) and chromosomal rearrangements, are frequently seen in PCNSL [108]. Similar to primary mediastinal large B-cell lymphoma, PCNSL cases have a relatively high frequency of 9p24.1/PD-L1/PD-L2 CNAs, whose structural bases cause overexpression of PD-L1/ PD-L2 and related immune evasion. It has been estimated that $67 \%$ of $\mathrm{EBV}^{-}$PCNSL cases exhibit 9p24.1/ $P D-L 1 / P D-L 2$ copy gain and CNA-associated increased expression. EBV triggering PD-1 upregulation is an additional mechanism in $\mathrm{EBV}^{+}$PCNSL. These indicate the potential of checkpoint inhibitors for PCNSL treatment [108].

A retrospective study investigated whether PD-L1 and PD-L2 are expressed at lower levels on PCNSL tumor cells than on peritumoral macrophages [109]. High tumoral PD-L1 signaling and low PD- $1^{+} \mathrm{CD}^{+} \mathrm{T}$ cell infiltration were indicated to be associated with an inferior prognosis in PCNSL [110, 111]. A pilot study showed that nivolumab (an anti-PD-1 antibody) produced superior clinical and radiographic responses in five $r / r$ PCNSL or secondary CNS lymphoma (SCNSL) patients. The regimens used in the study were not identical. Only one patient was receiving corticosteroid treatment at the time of nivolumab administration, while the others were administered nivolumab immediately after radiotherapy or ASCT [77]. Another $\mathrm{r} / \mathrm{r}$ PCNSL patient was reported to be successfully treated with nivolumab during maintenance. Even though the patient's archival tumor tissue showed no expression of PD-L1/PD-L2 and no amplification of the PD-L1 locus on 9p24.1, the patient achieved durable remission after a 3rd round of ASCT with nivolumab maintenance [112].

\section{BBB permeabilization}

Another potential approach is to permeabilize the $\mathrm{BBB}$ by targeting aminopeptidase N (CD13), a membranebound metalloproteinase upregulated in tumor angiogenesis [113]. By fusing the $\mathrm{N}$ terminus of human tumor necrosis factor (TNF) $\alpha$ with CNGRCG, a protein called NGR-hTNF was generated and was able to recognize CD13 and increase leakage from the vasculature to tumor tissue, resulting in an enhancement in antitumor effects [114].

CD13 is widely expressed on tumor vessels, epithelia, kidney tissue and myeloid cells. However, only the antiCD13 VM15 isoform can recognize NGR-TNF, which is highly dependent on the NGR domain [115]. Synergistic tumor vessel damage and tumor-eradicating function were observed after the coadministration of NGR-TNF with chemotherapeutics (doxorubicin, cisplatin, paclitaxel and gemcitabine) or other antitumor cytokines (INF- $\gamma$ and endothelial-monocyte activating polypeptide II) [116-118].

A phase II trial showed that the combination of lowdose NGR-hTNF with a standard R-CHOP regimen produced a remarkable response in $\mathrm{r} / \mathrm{r}$ PCNSL patients $[119,120]$. NGR-hTNF was administered from cycles 26 at a dose of $0.8 \mu \mathrm{g} / \mathrm{m}^{2} 2$ hours before CHOP21 in a 1hour infusion. NGR-hTNF/R-CHOP was well tolerated, and no unexpected toxicities, toxicity-related course interruptions or dose reductions occurred. Among all cycles, there were sixteen episodes of serious AEs, including seizures, deep venous thrombosis, infection, syncope, constipation, febrile neutropenia and left ventricular function reduction. The ORR was $75 \%$ (11 CRs and 10 PRs among 28 patients), which has restored interest in using R-CHOP to treat CNSL [78].

\section{Chimeric antigen receptor (CAR) T cells}

CAR-T cells have been used to successfully treat B-cell leukemia and lymphoma, primarily by integrating domains for CD19 recognition and $\mathrm{T}$ cell activation to eradicate CD19-expressing malignant cells [121]. However, their potential in PCNSL has not yet been thoroughly explored, primarily because of treatment-related 
AEs (TRAEs), especially CAR-T cell-related encephalopathy syndrome (CRES).

Cytokine release syndrome (CRS) and CRES are the major toxicities of CAR-T cell therapy, but the underlying mechanisms are different. The severity of CRES may be associated with the number of activated $\mathrm{T}$ cells and levels of related cytokines in the CNS. In a rhesus macaque model injected with CD20 CAR-T cells and non-CAR- $\mathrm{T}$ cells, widespread intraparenchymal $\mathrm{T}$ cell infiltration comprising both CAR-T cells and non-CAR$\mathrm{T}$ cells was observed in all brain regions. However, the expression of the integrin VLA4 in CAR-T cells was 1.52 times of that in non-CAR-T cells, indicating that the CAR-T cells were more capable of homing into the brain. The levels of multiple proinflammatory cytokines, including IL-6, IL-2, GM-CSF, and VEGF, were elevated in the CSF by 478-, 10-, 8.2- and 6.3-fold, respectively [122]. These asymmetric increases in cerebral proinflammatory cytokine levels were also detected in an acute lymphocytic leukemia patient given CD19 CAR-T cell treatment [123].

IL-6, the major pathogenic macrophage/monocyte-released cytokine, functions as a proinflammatory or antiinflammatory factor via soluble IL-6R-mediated "transsignaling" or membrane-bound IL-6R-mediated "cis-signaling", respectively, and trans-signaling results in a high level of IL-6 and affects almost all types of cells [124]. Thus, tocilizumab, a humanized anti-IL-6-receptor (IL6R) monoclonal antibody (mAb), has been applied to block IL-6 receptor to manage hypotension, hypoxia and widespread organ dysfunction [125]. In an SGM3 mouse model established with patient-derived $\mathrm{CD} 19^{+} \mathrm{CD} 44 \mathrm{v6}^{+}$ ALL-CM cells, the mice were coinjected with nHuSGM3 $\mathrm{T}$ cells transduced with the CD44v6.28z CAR or CD19.28z CAR. Tocilizumab or anakinra (an IL-1 receptor antagonist) was administered just before CAR-T cell injection to prevent TRAEs. Interestingly, the mice treated with tocilizumab showed a sudden lethal neurologic syndrome on days 27-33, while those treated with anakinra did not, indicating that IL-1 signaling activation is the key mechanism in CAR-T cell-related neurotoxicity [126].

Recently, a high-throughput single-cell RNAsequencing study found that in the human brain, there is a small population coexpressing the B cell marker CD19 and the mural cell marker CD248. This population does not express CD79a or $\alpha$ SMA, highlighting that the cells are indeed pericytes coexpressing CD19. Interestingly, pericytes obtained from human lung tissues did not show CD19 staining. In a B cell-independent NSG mouse model, this specialized cerebral expression pattern caused damage to mural cells through off-tumor targeting by CD19 CAR-T cells and resulted in increased BBB permeabilization, as measured by Evans blue dye diffusion, during treatment with mCD19-28z CAR-T cells [127]. Additional supportive evidence for CD19 coexpression in mural cells is, in an experiment staining infiltrating $\mathrm{CD}^{+} \mathrm{T}$ cells in the CNS, a cerebral perivascular positive signal was seen in a patient with CD19CAR-T cell-related CRES, indicating that the brain perivascular tissues are also targeted by CAR-T cells [128]. However, $\mathrm{T}$ cell therapies specific for other $\mathrm{B}$ cell antigens, including CD20 and CD22, also exhibit treatmentrelated neurotoxicity in either humans or animals, highlighting the complicated underlying mechanism of immune effector cell-associated neurotoxicity syndrome (ICANS) [122, 129].

There have been some reports of CNS lymphoma showing promising outcomes with CAR-T cell therapy. A 67-year-old patient with PCNSL was treated with CD19 CAR-T cells and CD70 CAR-T cells. The patient had symptomatic improvement and obtained CR after one month. CART19 and CART70 cells were detectable in 10 months. No CRS and CRES occurred [79]. FDAapproved axicabtagene ciloleucel and lisocabtagene maraleucel (liso-cel) showed response to SCNSL [80, 81]. Compared to the patients without CNS involvement, the SCNSL patients had a decreased incidence of CRS and an increased incidence of grade 3-4 ICANS with liso-cel treatment [81]. Considering the function of IL-6 in CRS and CRES, some studies have reported preventing TRAEs by silencing IL- 6 signaling. Adding a short hairpin RNA expression cassette specific for IL-6 to a conventional CAR vector significantly reduced monocytereleased IL-6 levels and did not cause ICANS in a pilot study including 3 CNSL patients [130, 131].

\section{Future perspectives}

In the rituximab era, the overall therapeutic status of PCNSL patients lags far behind that of non-CNS DLBCL patients, resulting from the existence of a physiological barrier and unique pathology. The activated B-cell subtype with mutations in MYD88 and CD79B suggests that the genetic origin of PCNSL is distinct from that of other non-CNS DLBCLs [14]. However, there is no biomarker-oriented regimen currently being carefully developed for this disease entity. Future studies will focus on how to determine the optimal targeted chemoimmunotherapy by molecular stratification. A few questions need to be answered. For example, what is the appropriate schedule for combining HD-MTX, BTKis and iMiDs in such a disease commonly occurring in elderly patients? Is it necessary to apply antifungal prophylaxis when combining BTKis and HD chemotherapy? Which targeted agent is most suitable for induction or maintenance? How can ICANS be controlled during CAR-T 
cell therapy? A more precise stratification system depending on age, performance status, molecular pathological findings, genetic profile and cellular bioinformation needs to be developed.

\section{Conclusions}

In the context of HD-MTX-based chemotherapy, inclusion of rituximab during induction and thiotepaconditioned ASCT or WBRT during consolidation are currently standard choices for ND PCNSL. With the introduction of more targeted therapy focused on BCR activation and immune microenvironment modulation, the outcome of PCNSL patients has recently improved (Fig. 1). The optimal combination of novel targeted therapies and HD-MTX backbone in frontline will build a "stat-of-art" strategy in this rare malignancy.

\begin{abstract}
Abbreviations
a: Associated conditions collected from the public data sources of drugbank (https://www.drugbank.ca/drugs); A, AraC: Cytarabine; ALT: Alanine aminotransferase; APTT: Activated partial thromboplastin time; ASCT: Autologous hematopoietic stem cell transplantation; BCNU: Carmustine; BCR: B-cell antigen receptor; BBB: Blood-brain barrier; BTKi: Bruton tyrosine kinase inhibitor; c: Corrected for protein binding; CART: Chimeric antigen receptor T cells; con: Consolidation;

CHOP: Cyclophosphamide, doxorubicin, vincristine, prednisone; CLL: Chronic lymphocytic leukemia; CNS: Central nervous system; CR: Complete remission; CRES: CAR-T cell-related encephalopathy syndrome; CRS: Cytokine release syndrome; CRu: Complete remission unconfirmed; CSF: Cerebrospinal fluid; DA-TEDDi-R: Dose adjusted etoposide, temozolomide, liposomal doxorubicin, dexamethasone, intrathecal cytarabine; DLBCL: Diffuse large B-cell lymphoma; DXM: Dexamethasone; EBV: Epstein-Barr virus; EFS: Event-free survival; F: Fotemustine; HD-MTX: High dose methotrexate; I: Ifosfamide; IBER: Ibrutinib, rituximab, ifosfamide and etoposide; ICANS: Immune effector cell-associated neurotoxicity syndrome; IgH: Immunoglobulin heavy chain; iMiD: Immunomodulatory drugs; iv: Intravenous; M, MTX: Methotrexate; MMSE: Mini Mental State Examinations; MRE: Methotrexate, rituximab, and etoposide; MV: Molecular weight; NA: Not available; NCCN: National comprehensive cancer network; NCR: No complete remission; ND: Newly diagnosed; NGR-hTNF: Tumor necrosis factor-a coupled with CNGRCG peptide; non-GCB: Non-germinal center B-cell-like type; ORR: Overall response rate; OS: Overall survival; p: Nonhuman primates; PCNSL: Primary central nervous system lymphoma; PD-1: Programmed cell death protein-1; PFS: Progression-free survival; PR: Partial remission; Pred: Prednisone; Pro: Procarbazine; PVRL: Primary vitreoretinal lymphoma; QoL: Quality of life R: Rituximab; r/r: Refractory/relapse; RCT: Randomized control trial; RMVP: Rituximab, methotrexate, procarbazine and vincristine; RT: Radiotherapy; SCNSL: Secondary central nervous system lymphoma; T: Thiotepa; Ten: Teniposide; TRAE: Treatment-related adverse effect; TMZ: Temozolomide; WBRT: Whole brain radiotherapy; w/w: Wait and watch; V: Vincristine; VP16: Etoposide
\end{abstract}

\section{Acknowledgements}

The authors specially thank Dr. Fan Liang (Obstetrics \& Gynecology Hospital, Fudan University) for kindly helping draw Fig. 1.

\section{Authors' contributions}

TC and YM conceived the design of the review. TC, YM and YY wrote the manuscript. All authors contributed to drafting and revising the article. All authors read and approved the final manuscript.

\section{Funding}

This project was supported by the National Natural \& Science Foundation of China (No.81870081), Program for Outstanding Medical Academic Leader of Shanghai (No.2019LJ05), Shanghai Collaborative Innovation Program on Regenerative Medicine and Stem Cell Research (No.2019CXJQ01) and
Translational Research Grant of the National Clinical Research Center for Hematologic Diseases (No.2020ZKMB03) to Tong Chen.

\begin{abstract}
Availability of data and materials
The registered BTKi trials of CNS lymphoma were sourced from the website Clinicaltrials.gov, accessed in October 2020. The associated pharmacokinetic conditions of the agent recommended by NCCN Guideline for PCNSL were collected from the public data sources of drugbank (https://www.drugbank. ca/drugs).
\end{abstract}

\section{Declarations}

Ethics approval and consent to participate

Not applicable.

\section{Consent for publication \\ Not applicable.}

\section{Competing interests}

The authors have declared no conflict of interest.

\section{Author details}

${ }^{1}$ Department of Hematology, Huashan Hospital, Fudan University, 12 Wulumuqi Middle Road, Shanghai 200040, China. ${ }^{2}$ Department of Pathology, Huashan Hospital, Fudan University, 12 Wulumuqi Middle Road, Shanghai 200040, China. ${ }^{3}$ Department of Neurosurgery, Huashan Hospital, Fudan University, 12 Wulumuqi Middle Road, Shanghai 200040, China.

Received: 17 February 2021 Accepted: 7 April 2021

Published online: 06 May 2021

\section{References}

1. Deckert M, Engert A, Bruck W, Ferreri AJ, Finke J, Illerhaus G, et al. Modern concepts in the biology, diagnosis, differential diagnosis and treatment of primary central nervous system lymphoma. Leukemia. 2011;25(12):1797-807.

2. Olson JE, Janney CA, Rao RD, Cerhan JR, Kurtin PJ, Schiff D, et al. The continuing increase in the incidence of primary central nervous system non-Hodgkin lymphoma: a surveillance, epidemiology, and end results analysis. Cancer. 2002;95(7):1504-10.

3. Sukswai N, Lyapichev K, Khoury JD, Medeiros LJ. Diffuse large B-cell lymphoma variants: an update. Pathology. 2020;52(1):53-67.

4. Lapointe $\mathrm{S}$, Perry A, Butowski NA. Primary brain tumours in adults. Lancet. 2018;392(10145):432-46.

5. Schmitz N. Treatment of primary CNS lymphoma. Blood. 2015;125(9):1360-1.

6. Harjunpaa A, Wiklund T, Collan J, Janes R, Rosenberg J, Lee D, et al. Complement activation in circulation and central nervous system after rituximab (anti-CD20) treatment of B-cell lymphoma. Leuk Lymphoma. 2001; 42(4):731-8

7. Ferreri AJ, Illerhaus $\mathrm{G}$. The role of autologous stem cell transplantation in primary central nervous system lymphoma. Blood. 2016;127(13):1642-9.

8. Gavrilovic IT, Hormigo A, Yahalom J, DeAngelis LM, Abrey LE. Long-term follow-up of high-dose methotrexate-based therapy with and without whole brain irradiation for newly diagnosed primary CNS lymphoma. I Clin Oncol. 2006;24(28):4570-4

9. Kasenda B, Loeffler J, Illerhaus G, Ferreri AJ, Rubenstein J, Batchelor TT. The role of whole brain radiation in primary CNS lymphoma. Blood. 2016;128(1): $32-6$.

10. Illerhaus G, Marks R, Ihorst G, Guttenberger R, Ostertag C, Derigs G, et al. High-dose chemotherapy with autologous stem-cell transplantation and hyperfractionated radiotherapy as first-line treatment of primary CNS lymphoma. J Clin Oncol. 2006;24(24):3865-70.

11. Woyach JA, Ruppert AS, Heerema NA, Zhao W, Booth AM, Ding W, et al. Ibrutinib Regimens versus Chemoimmunotherapy in Older Patients with Untreated CLL. N Engl J Med. 2018;379(26):2517-28.

12. Wang ML, Rule S, Martin P, Goy A, Auer R, Kahl BS, et al. Targeting BTK with ibrutinib in relapsed or refractory mantle-cell lymphoma. N Engl J Med. 2013;369(6):507-16.

13. Porter DL, Levine BL, Kalos M, Bagg A, June CH. Chimeric antigen receptormodified T cells in chronic lymphoid leukemia. N Engl J Med. 2011;365(8): 725-33. 
14. Lionakis MS, Dunleavy K, Roschewski M, Widemann BC, Butman JA, Schmitz $\mathrm{R}$, et al. Inhibition of B Cell Receptor Signaling by Ibrutinib in Primary CNS Lymphoma. Cancer Cell. 2017;31(6):833-43 e835.

15. Tun HW, Johnston PB, DeAngelis LM, Atherton PJ, Pederson LD, Koenig PA, et al. Phase 1 study of pomalidomide and dexamethasone for relapsed/ refractory primary CNS or vitreoretinal lymphoma. Blood. 2018;132(21):22408.

16. Barrantes-Freer A, Engel AS, Rodriguez-Villagra OA, Winkler A, Bergmann M, Mawrin C, et al. Diagnostic red flags: steroid-treated malignant CNS lymphoma mimicking autoimmune inflammatory demyelination. Brain Pathol. 2018;28(2):225-33.

17. Hiemcke-Jiwa LS, Leguit RJ, Snijders TJ, Jiwa NM, Kuiper JJW, de Weger RA, et al. Molecular analysis in liquid biopsies for diagnostics of primary central nervous system lymphoma: Review of literature and future opportunities. Crit Rev Oncol Hematol. 2018;127:56-65.

18. Swerdlow SH, Campo E, Pileri SA, Harris NL, Stein H, Siebert R, et al. The 2016 revision of the World Health Organization classification of lymphoid neoplasms. Blood. 2016;127(20):2375-90.

19. Sugita Y, Muta H, Ohshima K, Morioka M, Tsukamoto $Y$, Takahashi H, et al. Primary central nervous system lymphomas and related diseases: Pathological characteristics and discussion of the differential diagnosis. Neuropathology. 2016;36(4):313-24.

20. Chapuy B, Stewart C, Dunford AJ, Kim J, Kamburov A, Redd RA, et al. Molecular subtypes of diffuse large B cell lymphoma are associated with distinct pathogenic mechanisms and outcomes. Nat Med. 2018;24(5):679-90.

21. Schmitz R, Wright GW, Huang DW, Johnson CA, Phelan JD, Wang JQ, et al. Genetics and Pathogenesis of Diffuse Large B-Cell Lymphoma. N Engl J Med. 2018;378(15):1396-407.

22. Ferreri AJ. How I treat primary CNS Iymphoma. Blood. 2011;118(3):510-22.

23. Sagoo MS, Mehta H, Swampillai AJ, Cohen VM, Amin SZ, Plowman PN, et al. Primary intraocular lymphoma. Surv Ophthalmol. 2014;59(5):503-16.

24. El-Khouly FE, van Vuurden DG, Stroink T, Hulleman E, Kaspers GJL, Hendrikse $\mathrm{NH}$. Veldhuijzen van Zanten SEM: Effective Drug Delivery in Diffuse Intrinsic Pontine Glioma: A Theoretical Model to Identify Potential Candidates. Front Oncol. 2017;7:254

25. Csordas K, Hegyi M, Eipel OT, Muller J, Erdelyi DJ, Kovacs GT. Comparison of pharmacokinetics and toxicity after high-dose methotrexate treatments in children with acute lymphoblastic leukemia. Anticancer Drugs. 2013;24(2): 189-97.

26. Tetef ML, Margolin KA, Doroshow JH, Akman S, Leong LA, Morgan RJ Jr, et al. Pharmacokinetics and toxicity of high-dose intravenous methotrexate in the treatment of leptomeningeal carcinomatosis. Cancer Chemother Pharmacol. 2000;46(1):19-26.

27. Rubenstein $J$, Combs D, Rosenberg J, Levy A, McDermott M, Damon L, et al. Rituximab therapy for CNS lymphomas: targeting the leptomeningeal compartment. Blood. 2003;101(2):466-8

28. Petereit HF, Rubbert-Roth A. Rituximab levels in cerebrospinal fluid of patients with neurological autoimmune disorders. Mult Scler. 2009;15(2): 189-92.

29. Zhou Q, Guo P, Kruh GD, Vicini P, Wang X, Gallo JM. Predicting human tumor drug concentrations from a preclinical pharmacokinetic model of temozolomide brain disposition. Clin Cancer Res. 2007;13(14):4271-9.

30. Portnow J, Badie B, Chen M, Liu A, Blanchard S, Synold TW. The neuropharmacokinetics of temozolomide in patients with resectable brain tumors: potential implications for the current approach to chemoradiation. Clin Cancer Res. 2009;15(22):7092-8.

31. Goldwirt L, Zahr N, Farinotti R, Fernandez C. Development of a new UPLCMSMS method for the determination of temozolomide in mice: application to plasma pharmacokinetics and brain distribution study. Biomed Chromatogr. 2013;27(7):889-93.

32. DeAngelis LM, Seiferheld W, Schold SC, Fisher B, Schultz CJ. Radiation Therapy Oncology Group S: Combination chemotherapy and radiotherapy for primary central nervous system lymphoma: Radiation Therapy Oncology Group Study 93-10. J Clin Oncol. 2002;20(24):4643-8.

33. Jackson DV Jr, Sethi VS, Spurr CL, McWhorter JM. Pharmacokinetics of vincristine in the cerebrospinal fluid of humans. Cancer Res. 1981;41(4): 1466-8.

34. Heideman RL, Cole DE, Balis F, Sato J, Reaman GH, Packer RJ, et al. Phase I and pharmacokinetic evaluation of thiotepa in the cerebrospinal fluid and plasma of pediatric patients: evidence for dose-dependent plasma clearance of thiotepa. Cancer Res. 1989;49(3):736-41.
35. Papich MG. Lomustine. Saunders Handbook of Veterinary Drugs., 4th edn: W.B. Saunders; 2016.

36. Vassal G, Gouyette A, Hartmann O, Pico JL, Lemerle J. Pharmacokinetics of high-dose busulfan in children. Cancer Chemother Pharmacol. 1989;24(6): 386-90.

37. Egorin MJ, Kaplan RS, Salcman M, Aisner J, Colvin M, Wiernik PH, et al. Cyclophosphamide plasma and cerebrospinal fluid kinetics with and without dimethyl sulfoxide. Clin Pharmacol Ther. 1982;32(1):122-8.

38. Zucchetti M, Rossi C, Knerich R, Donelli MG, Butti G, Silvani V, et al. Concentrations of VP16 and VM26 in human brain tumors. Ann Oncol. 1991 2(1):63-6.

39. DeAngelis LM, Kreis W, Chan K, Dantis E, Akerman S. Pharmacokinetics of ara- $\mathrm{C}$ and ara- $\mathrm{U}$ in plasma and CSF after high-dose administration of cytosine arabinoside. Cancer Chemother Pharmacol. 1992;29(3):173-7.

40. Slevin ML, Piall EM, Aherne GW, Harvey VJ, Johnston A, Lister TA. Effect of dose and schedule on pharmacokinetics of high-dose cytosine arabinoside in plasma and cerebrospinal fluid. J Clin Oncol. 1983;1(9):546-51.

41. Goldwirt L, Beccaria K, Ple A, Sauvageon H, Mourah S. Ibrutinib brain distribution: a preclinical study. Cancer Chemother Pharmacol. 2018:81(4):783-9.

42. Rubenstein JL, Geng H, Fraser EJ, Formaker P, Chen L, Sharma J, et al. Phase 1 investigation of lenalidomide/rituximab plus outcomes of lenalidomide maintenance in relapsed CNS lymphoma. Blood Adv. 2018;2(13):1595-607.

43. Muscal JA, Sun Y, Nuchtern JG, Dauser RC, McGuffey LH, Gibson BW, et al. Plasma and cerebrospinal fluid pharmacokinetics of thalidomide and lenalidomide in nonhuman primates. Cancer Chemother Pharmacol. 2012; 69(4):943-7

44. Baker SD, Heideman RL, Crom WR, Kuttesch JF, Gajjar A, Stewart CF. Cerebrospinal fluid pharmacokinetics and penetration of continuous infusion topotecan in children with central nervous system tumors. Cancer Chemother Pharmacol. 1996;37(3):195-202.

45. Ginsberg S, Kirshner J, Reich S, Panasci L, Finkelstein T, Fandrich S, et al. Systemic chemotherapy for a primary germ cell tumor of the brain: a pharmacokinetic study. Cancer Treat Rep. 1981;65(5-6):477-83.

46. Kumthekar P, Grimm SA, Avram MJ, Kaklamani V, Helenowski I, Rademaker A, et al. Pharmacokinetics and efficacy of pemetrexed in patients with brain or leptomeningeal metastases. J Neurooncol. 2013;112(2):247-55.

47. Batchelor T, Carson K, O'Neill A, Grossman SA, Alavi J, New P, et al. Treatment of primary CNS lymphoma with methotrexate and deferred radiotherapy: a report of NABTT 96-07. J Clin Oncol. 2003;21(6):1044-9.

48. Chamberlain MC, Johnston SK. High-dose methotrexate and rituximab with deferred radiotherapy for newly diagnosed primary B-cell CNS lymphoma. Neuro Oncol. 2010;12(7):736-44.

49. Shah GD, Yahalom J, Correa DD, Lai RK, Raizer JJ, Schiff D, et al. Combined immunochemotherapy with reduced whole-brain radiotherapy for newly diagnosed primary CNS Iymphoma. J Clin Oncol. 2007;25(30):4730-5.

50. Morris PG, Correa DD, Yahalom J, Raizer JJ, Schiff D, Grant B, et al. Rituximab, methotrexate, procarbazine, and vincristine followed by consolidation reduced-dose whole-brain radiotherapy and cytarabine in newly diagnosed primary CNS lymphoma: final results and long-term outcome. J Clin Oncol. 2013;31(31):3971-9.

51. Mead GM, Bleehen NM, Gregor A, Bullimore J, Shirley D, Rampling RP, et al. A medical research council randomized trial in patients with primary cerebral non-Hodgkin lymphoma: cerebral radiotherapy with and without cyclophosphamide, doxorubicin, vincristine, and prednisone chemotherapy. Cancer. 2000;89(6):1359-70.

52. Ferreri AJ, Reni M, Foppoli M, Martelli M, Pangalis GA, Frezzato $M$, et al. High-dose cytarabine plus high-dose methotrexate versus high-dose methotrexate alone in patients with primary CNS Iymphoma: a randomised phase 2 trial. Lancet. 2009;374(9700):1512-20.

53. Omuro A, Chinot O, Taillandier L, Ghesquieres H, Soussain C, Delwail V, et al. Methotrexate and temozolomide versus methotrexate, procarbazine, vincristine, and cytarabine for primary CNS lymphoma in an elderly population: an intergroup ANOCEF-GOELAMS randomised phase 2 trial. Lancet Haematol. 2015;2(6):e251-9.

54. Ferreri AJ, Cwynarski K, Pulczynski E, Ponzoni M, Deckert M, Politi LS, et al. Chemoimmunotherapy with methotrexate, cytarabine, thiotepa, and rituximab (MATRix regimen) in patients with primary CNS lymphoma: results of the first randomisation of the International Extranodal Lymphoma Study Group-32 (IELSG32) phase 2 trial. Lancet Haematol. 2016;3(5):e217-27.

55. Wu J, Duan L, Zhang L, Sun Z, Fu X, Li X, et al. Fotemustine, teniposide and dexamethasone versus high-dose methotrexate plus cytarabine in newly 
diagnosed primary CNS lymphoma: a randomised phase 2 trial. J Neurooncol. 2018;140(2):427-34.

56. Bromberg JEC, Issa S, Bakunina K, Minnema MC, Seute T, Durian M, et al. Rituximab in patients with primary CNS lymphoma (HOVON 105/ALLG NHL 24): a randomised, open-label, phase 3 intergroup study. Lancet Oncol. 2019;20(2):216-28.

57. Thiel E, Korfel A, Martus P, Kanz L, Griesinger F, Rauch M, et al. High-dose methotrexate with or without whole brain radiotherapy for primary CNS lymphoma (G-PCNSL-SG-1): a phase 3, randomised, non-inferiority trial. Lancet Oncol. 2010;11(11):1036-47.

58. Ferreri AJM, Cwynarski K, Pulczynski E, Fox CP, Schorb E, La Rosee P, et al. Whole-brain radiotherapy or autologous stem-cell transplantation as consolidation strategies after high-dose methotrexate-based chemoimmunotherapy in patients with primary CNS lymphoma: results of the second randomisation of the International Extranodal Lymphoma Study Group-32 phase 2 trial. Lancet Haematol. 2017:4(11):e510-23.

59. Herrlinger $U$, Schafer $N$, Fimmers $R$, Griesinger F, Rauch $M$, Kirchen $H$, et al. Early whole brain radiotherapy in primary CNS lymphoma: negative impact on quality of life in the randomized G-PCNSL-SG1 trial. J Cancer Res Clin Oncol. 2017;143(9):1815-21.

60. Houillier C, Taillandier L, Dureau S, Lamy T, Laadhari M, Chinot O, et al. Radiotherapy or Autologous Stem-Cell Transplantation for Primary CNS Lymphoma in Patients 60 Years of Age and Younger: Results of the Intergroup ANOCEF-GOELAMS Randomized Phase II PRECIS Study. J Clin Oncol. 2019;37(10):823-33.

61. Rubenstein JL, Hsi ED, Johnson JL, Jung SH, Nakashima MO, Grant B, et al. Intensive chemotherapy and immunotherapy in patients with newly diagnosed primary CNS Iymphoma: CALGB 50202 (Alliance 50202). J Clin Oncol. 2013;31(25):3061-8.

62. Omuro A, Correa DD, DeAngelis LM, Moskowitz CH, Matasar MJ, Kaley TJ, et al. R-MPV followed by high-dose chemotherapy with TBC and autologous stem-cell transplant for newly diagnosed primary CNS lymphoma. Blood. 2015;125(9):1403-10.

63. Siegal T, Bairey O. Primary CNS Lymphoma in the Elderly: The Challenge. Acta Haematol. 2019;141(3):138-45.

64. Prica A, Chan K, Cheung MC. Combined modality therapy versus chemotherapy alone as an induction regimen for primary central nervous system lymphoma: a decision analysis. Br J Haematol. 2012;158(5):600-7.

65. Kepka L, Tyc-Szczepaniak D, Osowiecka K, Sprawka A, Trabska-Kluch B, Czeremszynska B. Quality of life after whole brain radiotherapy compared with radiosurgery of the tumor bed: results from a randomized trial. Clin Transl Oncol. 2018;20(2):150-9.

66. Alvarnas JC, Negrin RS, Horning SJ, Hu WW, Long GD, Schriber JR, et al. High-dose therapy with hematopoietic cell transplantation for patients with central nervous system involvement by non-Hodgkin's lymphoma. Biol Blood Marrow Transplant. 2000;6(3A):352-8.

67. Soussain C, Hoang-Xuan K, Taillandier L, Fourme E, Choquet S, Witz F, et al. Intensive chemotherapy followed by hematopoietic stem-cell rescue for refractory and recurrent primary CNS and intraocular lymphoma: Societe Francaise de Greffe de Moelle Osseuse-Therapie Cellulaire. J Clin Oncol. 2008;26(15):2512-8.

68. Abrey LE, Moskowitz CH, Mason WP, Crump M, Stewart D, Forsyth P, et al. Intensive methotrexate and cytarabine followed by high-dose chemotherapy with autologous stem-cell rescue in patients with newly diagnosed primary CNS lymphoma: an intent-to-treat analysis. J Clin Oncol. 2003;21(22):4151-6.

69. Strong JM, Collins JM, Lester C, Poplack DG: Pharmacokinetics of intraventricular and intravenous $\mathrm{N}_{1} \mathrm{~N}^{\prime}, \mathrm{N}^{\prime \prime}$-triethylenethiophosphoramide (thiotepa) in rhesus monkeys and humans. Cancer Res 1986, 46(12 Pt 1):6101-6104.

70. Grommes C, Pastore A, Palaskas N, Tang SS, Campos C, Schartz D, et al. Ibrutinib Unmasks Critical Role of Bruton Tyrosine Kinase in Primary CNS Lymphoma. Cancer Discov. 2017;7(9):1018-29.

71. Soussain C, Choquet S, Blonski M, Leclercq D, Houillier C, Rezai K, et al. Ibrutinib monotherapy for relapse or refractory primary CNS lymphoma and primary vitreoretinal lymphoma: Final analysis of the phase II 'proof-of-concept' iLOC study by the Lymphoma study association (LYSA) and the French oculocerebral lymphoma (LOC) network. Eur J Cancer. 2019;117:121-30.

72. Grommes C, Tang SS, Wolfe J, Kaley TJ, Daras M, Pentsova El, et al. Phase $1 \mathrm{~b}$ trial of an ibrutinib-based combination therapy in recurrent/refractory CNS lymphoma. Blood. 2019;133(5):436-45.

73. Chen F, Pang D, Guo H, Ou Q, Wu X, Jiang X, et al. Clinical outcomes of newly diagnosed primary CNS lymphoma treated with ibrutinib-based combination therapy: A real-world experience of off-label ibrutinib use. Cancer Med. 2020;9(22):8676-84.

74. Narita $Y$, Nagane M, Mishima K, Terui Y, Arakawa Y, Yonezawa H, et al. Phase I/II study of tirabrutinib, a second-generation Bruton's tyrosine kinase inhibitor, in relapsed/refractory primary central nervous system lymphoma. Neuro Oncol. 2021;23(1):122-33.

75. Vu K, Mannis G, Hwang J, Geng H, Rubenstein JL. Low-dose lenalidomide maintenance after induction therapy in older patients with primary central nervous system lymphoma. Br J Haematol. 2019;186(1):180-3.

76. Ghesquieres $\mathrm{H}$, Chevrier M, Laadhari M, Chinot $\mathrm{O}$, Choquet S, MoluconChabrot C, et al. Lenalidomide in combination with intravenous rituximab (REVRI) in relapsed/refractory primary CNS lymphoma or primary intraocular lymphoma: a multicenter prospective 'proof of concept' phase II study of the French Oculo-Cerebral lymphoma (LOC) Network and the Lymphoma Study Association (LYSA)dagger. Ann Oncol. 2019;30(4):621-8.

77. Nayak L, Iwamoto FM, LaCasce A, Mukundan S, Roemer MGM, Chapuy B, et al. PD-1 blockade with nivolumab in relapsed/refractory primary central nervous system and testicular lymphoma. Blood. 2017;129(23):3071-3.

78. Ferreri AJM, Calimeri T, Ponzoni M, Curnis F, Conte GM, Scarano E, et al. Improving the antitumor activity of R-CHOP with NGR-hTNF in primary CNS lymphoma: final results of a phase 2 trial. Blood Adv. 2020;4(15):3648-58.

79. Tu S, Zhou X, Guo Z, Huang R, Yue C, He Y, et al. CD19 and CD70 DualTarget Chimeric Antigen Receptor T-Cell Therapy for the Treatment of Relapsed and Refractory Primary Central Nervous System Diffuse Large BCell Lymphoma. Front Oncol. 2019;9:1350.

80. Abbasi A, Peeke S, Shah N, Mustafa J, Khatun F, Lombardo A, et al. Axicabtagene ciloleucel CD19 CAR-T cell therapy results in high rates of systemic and neurologic remissions in ten patients with refractory large B cell lymphoma including two with HIV and viral hepatitis. J Hematol Oncol. 2020;13(1):1.

81. Abramson JS, Palomba ML, Gordon LI, Lunning MA, Wang M, Arnason J, et al. Lisocabtagene maraleucel for patients with relapsed or refractory large B-cell lymphomas (TRANSCEND NHL 001): a multicentre seamless design study. Lancet. 2020;396(10254):839-52.

82. Low JT, Peters KB. Ibrutinib in primary central nervous system diffuse large B-cell lymphoma. CNS Oncol. 2020;9(1):CNS51.

83. Vassilev A, Ozer Z, Navara C, Mahajan S, Uckun FM. Bruton's tyrosine kinase as an inhibitor of the Fas/CD95 death-inducing signaling complex. J Biol Chem. 1999; 274(3):1646-56.

84. Satterthwaite AB, Lowell CA, Khan WN, Sideras P, Alt FW, Witte ON. Independent and opposing roles for Btk and lyn in B and myeloid signaling pathways. J Exp Med. 1998;188(5):833-44.

85. Brorson K, Brunswick M, Ezhevsky S, Wei DG, Berg R, Scott D. Stein KE: xid affects events leading to B cell cycle entry. J Immunol. 1997;159(1):135-43.

86. Honigberg LA, Smith AM, Sirisawad M, Verner E, Loury D, Chang B, et al. The Bruton tyrosine kinase inhibitor PCl-32765 blocks B-cell activation and is efficacious in models of autoimmune disease and B-cell malignancy. Proc Natl Acad Sci U S A. 2010;107(29):13075-80.

87. Treon SP, Tripsas CK, Meid K, Warren D, Varma G, Green R, et al. Ibrutinib in previously treated Waldenstrom's macroglobulinemia. N Engl J Med. 2015;372(15):1430-40.

88. Wilson WH, Young RM, Schmitz R, Yang Y, Pittaluga S, Wright G, et al. Targeting $B$ cell receptor signaling with ibrutinib in diffuse large $B$ cell lymphoma. Nat Med. 2015;21(8):922-6.

89. Ponader S, Chen SS, Buggy JJ, Balakrishnan K, Gandhi V, Wierda WG, et al. The Bruton tyrosine kinase inhibitor PCl-32765 thwarts chronic lymphocytic leukemia cell survival and tissue homing in vitro and in vivo. Blood. 2012;119(5):1182-9.

90. Wu J, Liu C, Tsui ST, Liu D. Second-generation inhibitors of Bruton tyrosine kinase. J Hematol Oncol. 2016;9(1):80.

91. Argyropoulos KV, Palomba ML. First-Generation and Second-Generation Bruton Tyrosine Kinase Inhibitors in Waldenstrom Macroglobulinemia. Hematol Oncol Clin North Am. 2018;32(5):853-64.

92. Bond DA, Maddocks KJ. Current Role and Emerging Evidence for Bruton Tyrosine Kinase Inhibitors in the Treatment of Mantle Cell Lymphoma. Hematol Oncol Clin North Am. 2020;34(5):903-21.

93. Chamoun K, Choquet S, Boyle E, Houillier C, Larrieu-Ciron D, Al Jijakli A, et al. Ibrutinib monotherapy in relapsed/refractory CNS lymphoma: A retrospective case series. Neurology. 2017:88(1):101-2.

94. Schmidt NW, Thieu VT, Mann BA, Ahyi AN, Kaplan MH. Bruton's tyrosine kinase is required for TLR-induced IL-10 production. J Immunol. 2006;177(10):7203-10.

95. Bercusson A, Colley T, Shah A, Warris A, Armstrong-James D. Ibrutinib blocks Btk-dependent NF-kB and NFAT responses in human macrophages during Aspergillus fumigatus phagocytosis. Blood. 2018;132(18):1985-8. 
96. Dubovsky JA, Beckwith KA, Natarajan G, Woyach JA, Jaglowski S, Zhong Y, et al. Ibrutinib is an irreversible molecular inhibitor of ITK driving a Th1selective pressure in T lymphocytes. Blood. 2013;122(15):2539-49.

97. Tillman BF, Pauff JM, Satyanarayana G, Talbott M, Warner JL. Systematic review of infectious events with the Bruton tyrosine kinase inhibitor ibrutinib in the treatment of hematologic malignancies. Eur J Haematol. 2018;100(4):325-34.

98. Brown JR. How I treat CLL patients with ibrutinib. Blood. 2018;131(4):379-86.

99. Wu L, Adams M, Carter T, Chen R, Muller G, Stirling D, et al. Bartlett JB: lenalidomide enhances natural killer cell and monocyte-mediated antibodydependent cellular cytotoxicity of rituximab-treated CD20+ tumor cells. Clin Cancer Res. 2008;14(14):4650-7.

100. Yang Y, Shaffer AL 3rd, Emre NC, Ceribelli M, Zhang M, Wright G, et al. Exploiting synthetic lethality for the therapy of $A B C$ diffuse large $B$ cell lymphoma. Cancer Cell. 2012;21(6):723-37.

101. Li Z, Qiu Y, Personett D, Huang P, Edenfield B, Katz J, et al. Pomalidomide shows significant therapeutic activity against CNS lymphoma with a major impact on the tumor microenvironment in murine models. PLoS One. 2013; 8(8):e71754.

102. Zhu YX, Braggio E, Shi CX, Bruins LA, Schmidt JE, Van Wier S, et al. Cereblon expression is required for the antimyeloma activity of lenalidomide and pomalidomide. Blood. 2011;118(18):4771-9.

103. Armand P. Immune checkpoint blockade in hematologic malignancies. Blood. 2015;125(22):3393-400.

104. Ishida Y, Agata Y, Shibahara K, Honjo T. Induced expression of PD-1, a novel member of the immunoglobulin gene superfamily, upon programmed cell death. EMBO J. 1992;11(11):3887-95.

105. Dong H, Zhu G, Tamada K, Chen L. B7-H1, a third member of the B7 family, co-stimulates T-cell proliferation and interleukin-10 secretion. Nat Med. 1999;5(12):1365-9.

106. Freeman GJ, Long AJ, Iwai Y, Bourque K, Chernova T, Nishimura H, et al. Engagement of the PD-1 immunoinhibitory receptor by a novel B7 family member leads to negative regulation of lymphocyte activation. J Exp Med. 2000;192(7):1027-34

107. Latchman Y, Wood CR, Chernova T, Chaudhary D, Borde M, Chernova I, et al. PD-L2 is a second ligand for PD-1 and inhibits T cell activation. Nat Immunol. 2001;2(3):261-8.

108. Chapuy B, Roemer MG, Stewart C, Tan Y, Abo RP, Zhang L, et al. Targetable genetic features of primary testicular and primary central nervous system lymphomas. Blood. 2016;127(7):869-81.

109. Furuse M, Kuwabara H, Ikeda N, Hattori Y, Ichikawa T, Kagawa N, et al. PD-L1 and PD-L2 expression in the tumor microenvironment including peritumoral tissue in primary central nervous system lymphoma. BMC Cancer. 2020;20(1):277

110. Kim S, Nam SJ, Park C, Kwon D, Yim J, Song SG, et al. High tumoral PD-L1 expression and low PD-1(+) or CD8(+) tumor-infiltrating lymphocytes are predictive of a poor prognosis in primary diffuse large B-cell lymphoma of the central nervous system. Oncoimmunology. 2019;8(9):e1626653.

111. Cho H, Kim SH, Kim SJ, Chang JH, Yang WI, Suh CO, et al. Programmed cell death 1 expression is associated with inferior survival in patients with primary central nervous system lymphoma. Oncotarget. 2017;8(50):8731728.

112. Terziev D, Hutter B, Klink B, Stenzinger A, Stogbauer F, Glimm H, et al. Nivolumab maintenance after salvage autologous stem cell transplantation results in long-term remission in multiple relapsed primary CNS lymphoma. Eur J Haematol. 2018;101(1):115-8.

113. Curnis F, Sacchi A, Borgna L, Magni F, Gasparri A, Corti A. Enhancement of tumor necrosis factor alpha antitumor immunotherapeutic properties by targeted delivery to aminopeptidase N (CD13). Nat Biotechnol. 2000;18(11): 1185-90.

114. van Laarhoven HW, Gambarota G, Heerschap A, Lok J, Verhagen I, Corti A, et al. Effects of the tumor vasculature targeting agent NGR-TNF on the tumor microenvironment in murine lymphomas. Invest New Drugs. 2006; 24(1):27-36.

115. Curnis F, Arrigoni G, Sacchi A, Fischetti L, Arap W, Pasqualini R, et al. Differential binding of drugs containing the NGR motif to CD13 isoforms in tumor vessels, epithelia, and myeloid cells. Cancer Res. 2002;62(3):867-74.

116. Sacchi A, Gasparri A, Curnis F, Bellone M, Corti A. Crucial role for interferon gamma in the synergism between tumor vasculature-targeted tumor necrosis factor alpha (NGR-TNF) and doxorubicin. Cancer Res. 2004;64(19): 7150-5.
117. Crippa L, Gasparri A, Sacchi A, Ferrero E, Curnis F, Corti A. Synergistic damage of tumor vessels with ultra low-dose endothelial-monocyte activating polypeptide-II and neovasculature-targeted tumor necrosis factoralpha. Cancer Res. 2008;68(4):1154-61.

118. Sacchi A, Gasparri A, Gallo-Stampino C, Toma S, Curnis F, Corti A. Synergistic antitumor activity of cisplatin, paclitaxel, and gemcitabine with tumor vasculature-targeted tumor necrosis factor-alpha. Clin Cancer Res. 2006; 12(1):175-82.

119. Ferreri AJM, Calimeri T, Conte GM, Cattaneo D, Fallanca F, Ponzoni M, et al. $\mathrm{R}-\mathrm{CHOP}$ preceded by blood-brain barrier permeabilization with engineered tumor necrosis factor-alpha in primary CNS Iymphoma. Blood. 2019;134(3): 252-62.

120. Nayak L, Batchelor TT. Is it time to revisit R-CHOP for primary CNS lymphoma? Blood. 2019;134(3):221-2.

121. Kochenderfer JN, Rosenberg SA. Treating B-cell cancer with T cells expressing anti-CD19 chimeric antigen receptors. Nat Rev Clin Oncol. 2013; 10(5):267-76.

122. Taraseviciute A, Tkachev V, Ponce R, Turtle CJ, Snyder JM, Liggitt HD, et al. Chimeric Antigen Receptor T Cell-Mediated Neurotoxicity in Nonhuman Primates. Cancer Discov. 2018;8(6):750-63.

123. Hu Y, Sun J, Wu Z, Yu J, Cui Q, Pu C, et al. Predominant cerebral cytokine release syndrome in CD19-directed chimeric antigen receptor-modified T cell therapy. J Hematol Oncol. 2016;9(1):70.

124. Neelapu SS, Tummala S, Kebriaei P, Wierda W, Gutierrez C, Locke FL, et al. Chimeric antigen receptor T-cell therapy - assessment and management of toxicities. Nat Rev Clin Oncol. 2018;15(1):47-62.

125. Brudno JN, Kochenderfer JN. Toxicities of chimeric antigen receptor T cells: recognition and management. Blood. 2016;127(26):3321-30.

126. Norelli M, Camisa B, Barbiera G, Falcone L, Purevdorj A, Genua M, et al. Monocyte-derived IL-1 and IL-6 are differentially required for cytokinerelease syndrome and neurotoxicity due to CAR T cells. Nat Med. 2018;24(6): 739-48.

127. Parker KR, Migliorini D, Perkey E, Yost KE, Bhaduri A, Bagga P, et al. SingleCell Analyses Identify Brain Mural Cells Expressing CD19 as Potential OffTumor Targets for CAR-T Immunotherapies. Cell. 2020;183(1):126-42.e17.

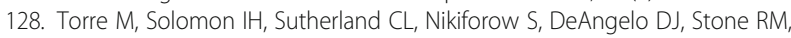
et al. Neuropathology of a Case With Fatal CAR T-Cell-Associated Cerebral Edema. J Neuropathol Exp Neurol. 2018;77(10):877-82.

129. Shalabi H, Wolters PL, Martin S, Toledo-Tamula MA, Roderick MC, Struemph $K$, et al. Systematic Evaluation of Neurotoxicity in Children and Young Adults Undergoing CD22 Chimeric Antigen Receptor T-Cell Therapy. J Immunother. 2018:41(7):350-8.

130. Chen LY, Kang LQ, Zhou HX, Gao HQ, Zhu XF, Xu N, et al. Successful application of anti-CD19 CAR-T therapy with IL-6 knocking down to patients with central nervous system B-cell acute lymphocytic leukemia. Transl Oncol. 2020;13(11):100838

131. Kang L, Tang X, Zhang J, Li M, Xu N, Qi W, et al. Interleukin-6-knockdown of chimeric antigen receptor-modified T cells significantly reduces IL- 6 release from monocytes. Exp Hematol Oncol. 2020;9:11.

\section{Publisher's Note}

Springer Nature remains neutral with regard to jurisdictional claims in published maps and institutional affiliations.

Ready to submit your research? Choose BMC and benefit from

- fast, convenient online submission

- thorough peer review by experienced researchers in your field

- rapid publication on acceptance

- support for research data, including large and complex data types

- gold Open Access which fosters wider collaboration and increased citations

- maximum visibility for your research: over $100 \mathrm{M}$ website views per year

At $\mathrm{BMC}$, research is always in progress.

Learn more biomedcentral.com/submission 